\title{
Use of SM-1 Monoclonal Antibody and Human Complement in Selective Killing of Small Cell Carcinoma of the Lung
}

Mack Mabry, Jonathan A. Speak, James D. Griffin, Rolf A. Stahel, and Samuel D. Bernal

Divisions of Medicine and Medical Oncology, Dana-Farber Cancer Institute and Harvard Medical School, Boston, Massachusetts 02115

\begin{abstract}
SM-1 is a murine monoclonal antibody strongly reactive with a cell membrane antigen of small cell carcinoma (SCC) of the lung but unreactive with the membrane of most other carcinomas and normal tissues including normal bone marrow. We have found that in the presence of human complement, SM-1 antibody is highly cytotoxic to SCC cells. Using three treatments with antibody and complement, more than $99 \%$ of SCC cells in culture were lysed, as determined by the chromium release and clonogenic assays. Similar efficiency of SCC cell lysis was observed when one SM-1 antibody treatment was followed by three treatments with human complement. In contrast, there was little antibody-dependent lysis of non-small cell lung cancer cells, other carcinomas, and leukemia cell lines. The amount of chromium released from normal bone marrow cells treated with SM-1 antibody and complement was minimal and was mainly due to the effect of complement alone. Clonogenic assays, including colony-forming unit-granulocytic/monocytic, erythroid burst-forming unit, and colony-forming unit-granulocytic/erythroid/monocytic/megakaryocytic, also showed no significant SM-1 antibody-dependent cytotoxicity on normal bone marrow precursors. Since SM-1 antibody is selectively cytotoxic to SCC cells in the presence of human complement, it is a potentially useful agent for the selective eradication of tumor cell contamination in marrows of patients with metastatic small cell lung cancer and possibly for in vivo serotherapy.
\end{abstract}

\section{Introduction}

Small cell carcinoma (SCC) ${ }^{1}$ of the lung displays a high capacity to metastasize to a large number of distant sites, including the adrenals, liver, bone marrow, and brain (1). In spite of high response rates to chemotherapy and radiation, long-term survivors are rare, mainly due to relapse followed by resistance to chemotherapeutic agents (2). In an attempt to overcome drug resistance, intensive chemotherapy regimens followed by autologous marrow support have been initiated (3-7). Patients who were selected for these regimens presumably had marrows free of tumor cell metastases. However, it has been shown that histological stains are limited in their ability to detect micrometastases of SCC to the bone marrow (8). In

Received for publication 2 November 1984 and in revised form 15 January 1985.

1. Abbreviations used in this paper: BFU-E, erythroid burst-forming unit; CFU, colony-forming unit; CFU-C, normal myeloid progenitor cells; GEMM, granulocytic/erythroid/monocytic/megakarocytic; SCC, small cell carcinoma.

J. Clin. Invest.

(C) The American Society for Clinical Investigation, Inc.

0021-9738/85/05/1690/06 $\$ 1.00$

Volume 75, May 1985, 1690-1695 future treatment programs, the prognostic significance of the infusion of bone marrows contaminated with SCC and the possibilities of clearing SCC from the marrow will need to be studied. In this paper, we describe the ability of a murine monoclonal antibody, SM-1, to selectively lyse SCC cells in the presence of human complement. The optimal concentrations of antibody and complement, incubation conditions, and cell target selectivity are examined.

\section{Methods}

\section{Cell lines}

All the cell lines were grown in Roswell Park Memorial Institute tissue culture medium 1640 (RPMI 1640) with $10 \%$ fetal calf serum and 1 $\mathrm{mM}$ glutamine. The SCC cell lines $\mathrm{OH} 1$ and $\mathrm{SW}-2$ and their reactivity with SM-1 antibody were previously described (9). Except for the data presented in Table I, experiments with SCC cells were performed using the SW-2 cell line. SLC6 is a human large cell carcinoma line developed in this laboratory. U1752 is a human squamous carcinoma of lung donated by Dr. J. Bergh, Sweden. T47D is a human breast carcinoma cell line provided by Dr. D. Kufe, Dana-Farber Cancer Institute, Boston, MA. CEM is a human lymphoblastic leukemia cell line obtained from Dr. H. Lazarus, Dana-Farber Cancer Institute. WI38 is a normal human fibroblast cell line obtained from the American Tissue Culture Collection, Rockville, Maryland.

\section{Preparation of antibody}

The preparation and propagation of the SM-1 hybridoma culture has been previously described (9). SM-1 cells were injected into Balb/c mice for the production of ascites. Ascitic fluid was centrifuged at $1,500 \mathrm{~g}$ for $20 \mathrm{~min}$. The clear supernatant was filtered on $0.2-\mu \mathrm{m}$ Nalgene filters. The antibody preparations were incubated at $50^{\circ} \mathrm{C}$ for $20 \mathrm{~min}$ to inactivate complement. Aliquots were then frozen and stored at $-80^{\circ} \mathrm{C}$. Before use in cytotoxicity experiments, the antibodies were diluted with RPMI medium to obtain the appropriate concentration of antibody.

Further purification of antibody from SM-1 supernatant or ascites was performed by affinity chromatography and gel filtration. ProtamineSepharose was prepared by cyanogen bromide coupling of protamine to Sepharose 4B. SM-1 ascites or supernatant was added to the gel and washed with dilute phosphate saline buffer $(0.03 \mathrm{M}$ phosphate, $0.025 \mathrm{M} \mathrm{NaCl}$ ). The washed gel was packed into a chromatography column and washed with dilute phosphate saline buffer to remove proteins other than IgM. The antibody was eluted with $0.08 \mathrm{M}$ phosphate buffer, $\mathrm{pH} 7.4$, with $1 \mathrm{M} \mathrm{NaCl}$. The eluate was concentrated in a dialysis bag covered with Aquacide (Calbiochem-Behring Corp., La Jolla, CA). SM-1 antibody was further purified by passing through a $120-\mathrm{cm}$ Sephacryl 300 column. The major antibody fractions were collected and tested for reactivity with SCC cells. Individual fractions with SCC reactivity were pooled and concentrated.

\section{Cytotoxicity of SM-1 antibody}

and complement toward human SCC

Chromium labeling. SCC or marrow cells were labeled with $200 \mu \mathrm{Ci} /$ $\mathrm{ml}$ of ${ }^{51} \mathrm{Cr}$ (New England Nuclear, Boston, MA) for $1 \mathrm{~h}$ at $37^{\circ} \mathrm{C}$. The cells were then washed with RPMI 1640 containing $1 \mathrm{mM}$ of glutamine and $4 \mathrm{mM}$ of Hepes buffer, and incubated in ice for $30 \mathrm{~min}$. After a second wash, the cells were transferred to RPMI medium containing 
$5 \%$ heat-inactivated human serum, $1 \mathrm{mM}$ glutamine, and $4 \mathrm{mM}$ Hepes. The cell concentration was $2 \times 10^{6}$ cells $/ \mathrm{ml}$.

Retreatment with antibody and complement. SM-1 antibody was diluted with RPMI medium containing $5 \%$ heat-inactivated human serum, $1 \mathrm{mM}$ glutamine, and $4 \mathrm{mM}$ Hepes. The antibody was added to the test cells and incubation was performed at $37^{\circ} \mathrm{C}$ for $30 \mathrm{~min}$. Human complement was then added to the wells and incubation was continued at $37^{\circ} \mathrm{C}$ for an additional $30 \mathrm{~min}$. For multiple antibody treatments, the cells were washed with RPMI medium containing 1 $\mathrm{mM}$ glutamine, $4 \mathrm{mM}$ Hepes, and heat-inactivated human serum between each treatment. After the final treatment, the cells were washed four times with RPMI medium. The amount of chromium associated with the cell pellet was determined in a gamma counter. The amounts of chromium released from the washes from the antibody treatment were determined and found to be consistent with the chromium remaining associated with the pellet. The chromium counts retained in the cells was then used in the calculation of cell lysis. Percent cell lysis was calculated by determining the proportion of chromium counts in antibody-treated cells (CrAb) relative to chromium counts in untreated cells (CrCon), after subtracting unreleasable chromium in cells lysed by freeze-thawing $(\mathrm{CrFt})$. Thus, percent lysis equals $100-100 \times(\mathrm{CrAb}-\mathrm{CrFt}) /(\mathrm{CrCon}-\mathrm{CrFt})$, or $(\mathrm{CrCon}-\mathrm{CrAb}) /$ $(\mathrm{CrCon}-\mathrm{CrFt}) \times 100$.

Determinations were done in triplicate. SD was $5-10 \%$ on each test.

Antibody treatment and replenishment with complement. The appropriate dilution of antibody was added to the test cells and the mixture was incubated at $37^{\circ} \mathrm{C}$ for $30 \mathrm{~min}$. Human complement was added to the cells at 30-min intervals while continuing the incubations at $37^{\circ} \mathrm{C}$. After the final treatment, the cells were washed four times with cold RPMI medium. Cell damage was determined by chromium release and clonogenic assays.

Clonogenic assays. For clonogenic assays with SCC cells, an exponentially growing culture of $\mathrm{OH}-1$ or SW-2 cells were dispersed into small clumps and allowed to grow in suspension for $1 \mathrm{~d}$. The cells are then disaggregated for a second time into single cells before treatment with antibody and/or complement. The cells are washed with growth medium, and seeded into plates with a $1.2 \%$ agar base and $1.3 \%$ methocel in medium with RPMI 1640 and $20 \%$ heatinactivated fetal calf serum. The seeding density included $10^{3}, 10^{4}$, $10^{5}, 10^{6}$, and $10^{7}$ cells/plate to increase accuracy in detecting several $\log$ reductions in colony formation.

Colony-forming assays for colony-forming unit (CFU)-granulocytic/ monocytic CFU-granulocytic/erythroid/monocytic/megakarocytic (GEMM) and erythroid burst-forming unit (BFU)-E were performed as previously described by one of the co-authors, Dr. J. D. Griffin (10).

\section{Results}

Number and duration of treatments with antibody and complement. We have previously determined by radioimmunoassay that binding of SM-1 antibody to intact SCC cells nears completion after a $45-\mathrm{min}$ incubation at $37^{\circ} \mathrm{C}$. We, therefore, devised an experimental procedure to expose the cells to antibody for at least $45 \mathrm{~min}$ and to vary the complement exposure time. This was accomplished by preincubating the SCC cells with SM-1 antibody for $30 \mathrm{~min}$, followed by incubation with complement for at least 15 min (range, 15$90 \mathrm{~min}$ ). When a single antibody exposure for $30 \mathrm{~min}$ was followed by a single complement treatment for 30,45 , or 90 min, the proportion of SCC cells lysed was 55,55 , and $60 \%$, respectively, as determined by the chromium release assay (Fig. 1). Thus, incubations with complement longer than 30 min did not significantly increase SCC lysis. However, increasing the number of treatments with antibody and complement while keeping the exposure time to complement constant (total, $90 \mathrm{~min}$ ) dramatically increased efficacy of SCC lysis.

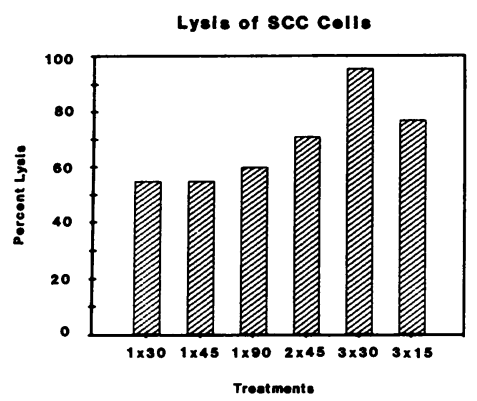

Figure 1. Effect of treatment schedule on lysis of SCC cells. The number and duration of exposure to SM- 1 antibody and complement ranged from one treatment for $30 \mathrm{~min}$ at $37^{\circ} \mathrm{C}(1 \times 30)$ to three treatments for $15 \mathrm{~min}(3$ $\times 15$ ). Cell lysis was measured by chromium release assay and expressed as the proportion of chromium counts released from antibody-treated cells relative to untreated controls. Optimal cell lysis was observed with three treatments for $30 \mathrm{~min}(3 \times 30)$. The average SD for triplicate samples was $5-10 \%$.

Whereas a single exposure to antibody followed by $90 \mathrm{~min}$ of complement $\left(\mathrm{Ab}+\mathrm{C}_{90}\right)$ resulted in $60 \%$ lysis, two treatments with antibody each followed by 45 -min treatments with complement $\left(\mathrm{Ab}+\mathrm{C}_{45}, \mathrm{Ab}+\mathrm{C}_{45}\right)$ resulted in $71 \%$ lysis (Fig. 1). A further improvement in lysis ( $>95 \%)$ was produced by three treatments with antibody followed by 30 -min complement exposure: $3 \times\left(\mathrm{Ab}+\mathrm{C}_{30}\right)$. Reducing the complement exposure time from 30 to $15 \mathrm{~min}, 3 \times\left(\mathrm{Ab}+\mathrm{C}_{15}\right)$, reduced $\mathrm{SCC}$ lysis to $77 \%$.

The other experiments described below on the optimum dilutions of antibody and complement and the temperature dependence, were performed using three treatments with antibody followed by 30 -min incubations with complement. We have since found, however, that the treatment schedule could be simplified further. Instead of repeating the antibody treatments, we examined the effect of a single 30 -min preincubation with SM-1 antibody followed by replenishment with complement. As shown in Fig. 2, the replenishment method (Ab $+\mathrm{C}_{30}+\mathrm{C}_{30}+\mathrm{C}_{30}$ ) resulted in comparable efficacy of cell lysis as the retreatment procedure, $3 \times\left(\mathrm{Ab}+\mathrm{C}_{30}\right)$. The comparability of the retreatment vs. replenishment methods held true also for the $3 \times 15$ and $2 \times 45$ complement exposure schedules.

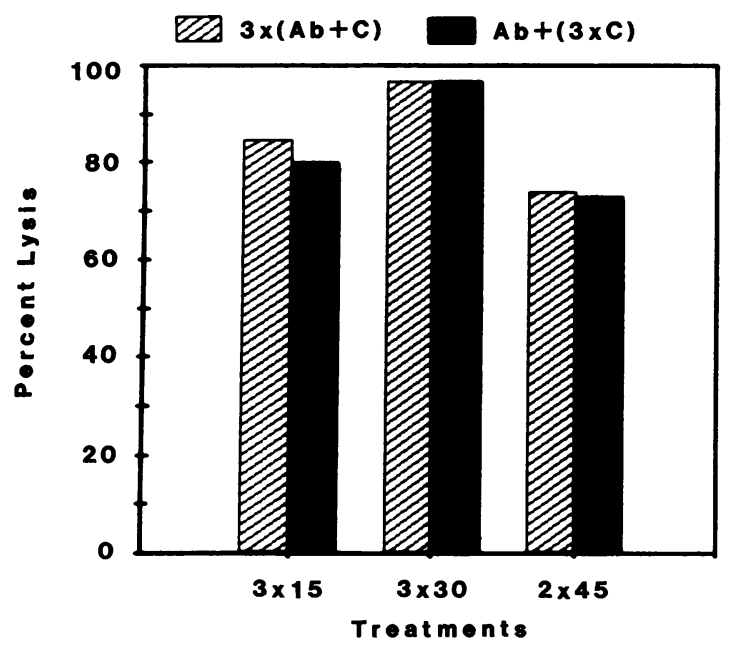

Figure 2. Effect of retreatment vs. replenishment in lysis of SCC cells. The retreatment method involves three exposures to antibody and complement: $3 \times(\mathrm{Ab}+\mathrm{C})$. The replenishment method includes one exposure to antibody and three additions of complement at 30min intervals: $A b+C_{30}+C_{30}+C_{30}$. The bars on the right indicate treatments with $2 \times(A b+C)$ and $A b+C_{45}+C_{45}$. 


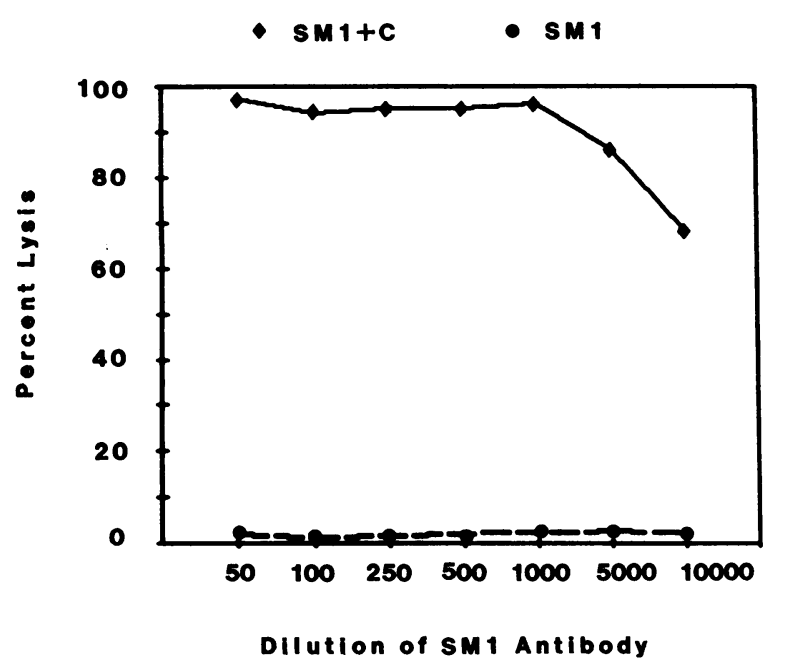

Figure 3. Percent lysis of SCC cells at different dilutions of SM-1 antibody. Human complement dilution was held constant at 1:10.

Antibody concentration. The effect of antibody concentration on cell lysis in the presence of a complement dilution of 1:10 is shown in Fig. 3. Using the three treatments, $3 \times(\mathrm{Ab}+\mathrm{C})$, SCC lysis remained at $95 \%$ or greater at dilutions of antibody from 1:50 to 1:1,000. A significant decline in efficiency of lysis was seen at dilutions of 1:5,000 or greater. Percent lysis was still $>70 \%$, even at dilutions of 10,000 . In contrast, three treatments with SM-1 antibody in the absence of complement resulted in a negligible level of cell lysis $(<3 \%)$, even at the highest concentrations of SM-1 antibody.

Complement concentration. Using SM-1 antibody dilution of $1: 100$, the effect of varying dilutions of human complement was determined (Fig. 4). The highest dilution of human complement that gave high levels of synergism with SM-1 antibody was 1:10, resulting in 99\% SCC lysis. Higher dilutions of complement resulted in a rapid decline in the efficiency of cell lysis. For example, cell lysis was reduced to $50 \%$ with complement dilutions between 1:40 and 1:50. By comparison,

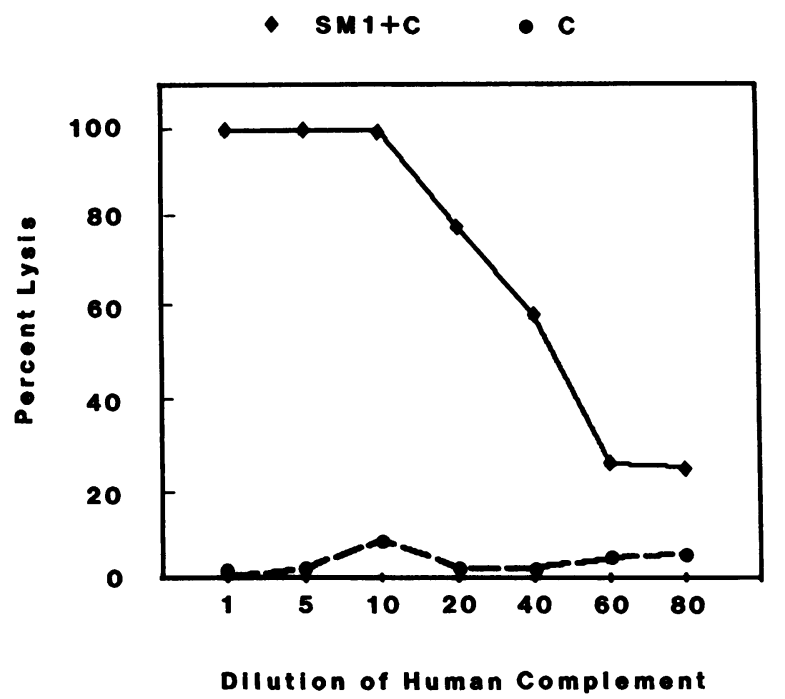

Figure 4. Percent lysis of SCC cells at different dilutions of human complement. SM-1 antibody dilution was held constant at 1:100.

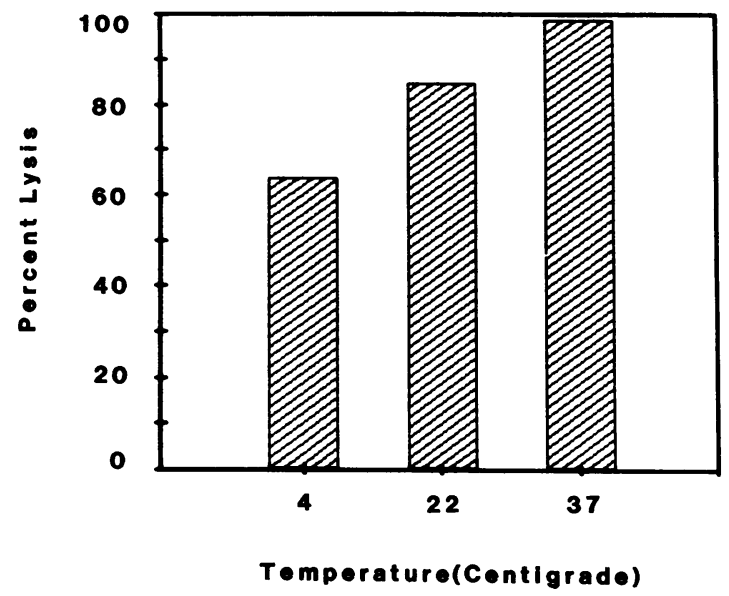

Figure 5. Effect of temperature on SCC cell lysis by SM-1 antibody and complement. The temperature used for incubation of antibody was varied. The cells were then washed and incubated in the presence of human complement at $37^{\circ} \mathrm{C}$.

rabbit complement was most effective at dilutions of 1:151:20 (99\% lysis); 1:50 dilution of rabbit complement produced $80 \%$ SCC lysis. Human complement in the absence of SM-1 antibody resulted in $<5 \%$ lysis of SCC cells even at low dilutions. The human complement used in these experiments was preadsorbed using SCC cells. When nonadsorbed human complement was used, the background lysis in the absence of SM-1 antibody was $\sim 2-5 \%$ higher than preadsorbed complement.

Temperature dependence. Using SM-1 antibody at 1:100 dilution and preadsorbed human complement, the optimal temperature for lytic activity was determined. As shown in Fig. 5, the highest lytic activity, greater than $99 \%$ was obtained at $37^{\circ} \mathrm{C}$. Lower temperatures of incubation resulted in much lower lytic activity. Thus only $65 \%$ of the cells were lysed at $4^{\circ} \mathrm{C}$ in otherwise optimal concentrations of antibody and complement for SCC cell lysis.

Cytotoxicity on cancer cell lines and normal cells. Table I summarizes the cytotoxic effects of SM- 1 antibody on different human cell lines. SW-2 and OH-1 are human SCC cell lines

Table I. Cell Lysis After Treatment with SM-1 Antibody and Complement

\begin{tabular}{llll}
\hline Cell target & SM-1 + C & SM-1 & C \\
\hline OH-1 (SCC) & 99 & 3 & 4 \\
SW-2 (SCC) & 99 & 2 & 5 \\
SL-6 (large cell cancer) & 6 & 2 & 5 \\
U1752 (squamous cancer) & 8 & 2 & 6 \\
T47D (breast cancer) & 4 & 1 & 5 \\
WI38 (normal fibroblast) & 4 & 1 & 4 \\
Normal bone marrow & 0 & 0 & 1
\end{tabular}

C; complement.

A control IgM antibody, 320, in the presence of complement lysed only $4 \%$ of OH-1 cells. Preadsorption of SM-1 antibody with $10^{6}$ $\mathrm{OH}-1$ cells $/ \mathrm{ml}$ reduced lysis of $\mathrm{OH}-1$ cells to $5 \%$ in the presence of complement. Results are averages of triplicate determinations. SD is $\sim 10 \%$. 
which we have previously shown to be strongly reactive with SM-1 antibody as determined by immunofluorescence and radioimmunoassay. Using SM-1 antibody and human complement, we were able to detect $99 \%$ lysis of these cells. In contrast, only $6-8 \%$ cell lysis was observed with non-small cell lung cancer cell lines such as SL6 (large cell undifferentiated carcinoma) and U-1752 (squamous carcinoma of the lung), which are unreactive with SM-1 antibody. Most of this background lytic activity was due to the effect of complement alone. Similarly, minimal SM-1 antibody-dependent lysis was observed with T47D (human breast carcinoma cell line) and WI38 (normal human fibroblasts).

Effect of SM-1 antibody on colony formation by SCC cells. The ability of SCC cells to form colonies in methocel was assessed after treatment with SM-1 antibody and replenishment with human complement (Table II). In these experiments, column-purified SM-1 antibody with a protein concentration of $24 \mathrm{mg} / \mathrm{ml}$ was found to have similar cytotoxic activity as pooled SM-1 ascites fluid with a total protein concentration of $40 \mathrm{mg} / \mathrm{ml}$. By varying the number of SCC cells plated on methocel from $10^{3}$ to $10^{7}$ cells/dish, we were able to reproducibly detect reduction in clonogenic cells by several orders of magnitude. This method of clonogenic assay was more sensitive in detecting the cytotoxic effect of antibodies than the chromium release assay. Greater than $99 \%$ reduction in clonogenic cells was observed at 1:100 dilution of SM-1 antibody and 1:10 dilution of human complement. Even at antibody dilution of 1:500, CFU was reduced to $98.7 \%$. Approximately $50 \%$ reduction of CFU was achieved at SM-1 dilution of 1:1,000. SM-1 antibody alone or human complement alone resulted in $2-4 \%$ reduction in CFU.

Effect of SM-1 antibody on bone marrow cells. In addition to the chromium release assays, clonogenic assays were performed to detect the effect of SM-1 antibody and human complement on normal bone marrow precursors. As shown in Table III, the different assays for colony formation by

Table II. Effect of SM-1 Antibody and Complement on SCC Colony Formation

\begin{tabular}{ll}
\hline Incubation mixture & $\begin{array}{l}\text { Reduction in } \\
\text { SCC CFUs }\end{array}$ \\
\hline & (\% of control) \\
SM-1 (1:100) + complement $(1: 10)$ & 99.1 \\
SM-1 (1:500) + complement $(1: 10)$ & 98.7 \\
SM-1 (1:1000) + complement $(1: 10)$ & 57.9 \\
SM-1 (1:5000) + complement $(1: 10)$ & 1.9 \\
SM-1 (1:100) & 2 \\
Complement (1:10) & 4 \\
SM-1 (1:100) + heat-inactivated complement & 4 \\
\end{tabular}

The reduction of CFU was calculated relative to untreated controls. The cloning efficiency of SW-2 cells was $1 \%$. The seeding density was $10^{3}$ cells/plate for untreated controls and for cells treated with antibody or complement alone. When high titers of antibody and complement were used, the seeding density was varied from $10^{3}$ to $10^{7}$ cells/plate to increase accuracy in detecting several log reductions in colony formation. The colony counts from plates with at least 50 colonies from the lowest seeding density were used to calculate percent reduction in CFU. Results are averages of triplicate cultures. SD is $\sim 3 \%$.
Table III. Effect of SM-1 Antibody and Complement on Colony Formation by Normal Bone Marrow Cells

\begin{tabular}{lll}
\hline & Control & SM-1 + complement \\
\hline & No. of colonies/dish & No. of colonies/dish \\
CFU-C & 54 & 58 \\
CFU-C & 14 & 12 \\
BFU-E & 27 & 26 \\
BFU-E & 18 & 16 \\
CFU-GEMM & 7 & 6
\end{tabular}

Results are averages of duplicate cultures. SD is $<25 \%$.

marrow cells including normal myeloid progenitor cells (CFUC), BFU-E, and CFU-GEMM did not reveal significant reduction in colony formation after three treatments with SM-1 antibody and human complement. The low level of colony reduction (one or two colonies) observed in some plates could be accounted for by the effect of complement alone.

Effect of SM-1 antibody on mixtures of SCC and normal bone marrow cells. Although SM-1 antibody was very efficient in lysis of SCC cells and had little effect on normal bone marrow cells, we needed to determine the efficiency of SCC cell lysis in the presence of bone marrow cells since this would better simulate the conditions in a clinical marrow specimen with SCC metastasis. SCC cells were labeled with ${ }^{51} \mathrm{Cr}$, washed, and then mixed with unlabeled marrow cells from normal volunteers. As shown in Fig. 6, when the antibody volume was held constant and increasing numbers of bone marrow cells were added to SCC cells, the efficiency of SCC cell lysis

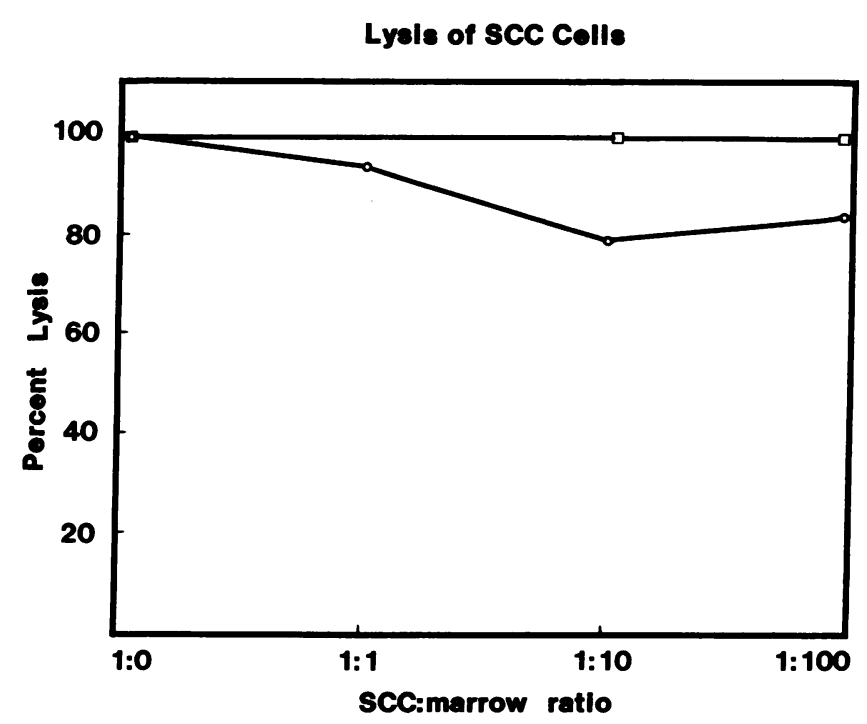

Figure 6. Lysis of SCC cells in mixtures of SCC and marrow cells. The ability of SM-1 antibody and human complement to lyse SCC cells in the presence of normal human bone marrow cells was determined by prelabeling SCC cells with chromium and measuring chromium release. The open squares represent SCC cell lysis at different ratios of SCC/marrow cells using a constant ratio of antibody/total cell number at $1 \mathrm{ml}: 10^{5}$ cells. The antibody protein concentration was $24 \mathrm{mg} / \mathrm{ml}$. The open circles represent cell lysis using a constant ratio of antibody $/ \mathrm{SCC}$ at $1 \mathrm{ml}: 10^{5}$ cells but adding increasing numbers of normal marrow cells. 
was reduced. However, when the total cell concentration was kept at $10^{5}$ cells $/ \mathrm{ml}$, high efficiency of SCC cell lysis was maintained ( $99 \%$ or greater) even at ratios of 1 SCC:100 marrow cells.

\section{Discussion}

SM-1 is a murine monoclonal IgM antibody which has been found to be strongly reactive with a cell membrane antigen found on human small cell lung carcinomas. The antibody was found to be generally unreactive with normal tissues such as lung parenchyma, liver, bronchial epithelium, brain, kidney, and bone marrow cells. Tumors other than small cell carcinoma of the lung, including those with neural characteristics such as neuroblastoma, adrenal carcinoma, melanoma, and bronchial carcinoid are usually unreactive. By immunofluorescence and immunoperoxidase staining of tumor-frozen sections, we have recently found that SM-1 antibody is reactive with $25 / 25$ SCC tumors and that the cells within a given tumor are uniformly stained with the antibody. The characteristics of this antibody, strong reactivity with SCC cells, uniform reactivity, and relative specificity, make it ideal as a diagnostic tool and possibly for therapy. We previously described the usefulness of SM-1 antibody in detecting metastasis of SCC cells to the bone marrow (8). In this paper, we describe the selective toxicity of SM-1 antibody towards SCC cells in the presence of human complement.

The use of human complement was emphasized in these studies for several reasons. Human serum is readily available in large amounts and at low cost as a by-product in the preparation of packed erythrocytes in hospital blood banks. This is particularly important if large volumes of complement are needed for clinical application. If antitumor antibodies are to be used for eradication of metastatic tumor in human marrows in the presence of complement, the use of human complement (perhaps from the patient's own serum) may avoid allergic reactions from reinfusion of heterologous proteins. We have also found that human complement produces lower levels of nonspecific, antibody-independent lysis of normal bone marrow cells than rabbit complement. The potential for in vivo serotherapy with monoclonal antibodies (even those which are not conjugated with a cytotoxic drug) would be strengthened if a specific antibody is able to fix human complement.

Although our data show that SCC cells, similar to leukemia cells (11), are efficiently lysed with three treatments of antibody and complement, we have found that it is not necessary to expose the SCC cells to multiple antibody treatments to achieve efficient lysis. It appears that complement is exhausted in the reaction mixture after $30 \mathrm{~min}$. This exhaustion of complement is the likely explanation for the requirement of repeated treatments because we find that the lytic efficiency of one antibody treatment followed by three replenishments with complement every $\mathbf{3 0} \mathrm{min}$ is comparable to lysis produced by three treatments with both antibody and complement. The efficacy of a single antibody treatment is particularly important if treatment of large volumes of cells is being considered.

The ability of SM-1 antibody to lyse SCC cells efficiently was maintained even with ratios of 1 SCC: 100 marrow cells, as long as the total cell concentration was kept low relative to antibody volume. The ratio of 1 SCC: 100 marrow cells was used in these experiments because this is a ratio we have observed in several clinical specimens examined with SM-1 antibody. We have also observed, in a few instances, ratios of up to 1 SCC:10 marrow cells. Using a ratio of 1 SCC:100 marrow cells and keeping the cell concentration at $10^{5}$ cells/ $\mathrm{ml}$, SCC lysis was maintained at $99 \%$. However, when the concentration of bone marrow cells was increased to $>10^{5}$ cells/ml with 1 SCC:100 marrow cells, lysis of SCC cells was reduced to $85 \%$. Why SCC lysis is inhibited in the presence of a high concentration of marrow cells is not clear but may be due to nonspecific inhibitors of antibody and/or complement. Complement inhibitors in short-term cultures of leukocytes have been previously described (2). This inhibition of SCC lysis can be overcome by using large volumes of antibody and complement. The antibody dilutions which are effective in SCC lysis are between 1:100 and 1:1,000. The optimum dilution of human complement is $1: 10$. If $10^{10}$ marrow cells are to be treated, one would need between 100 and $1,000 \mathrm{ml}$ of antibody and 10 liters of human serum to keep the cell concentration at $10^{5}$ cells $/ \mathrm{ml}$. These amounts of antibody and serum can be obtained easily. The high cytotoxic titer of SM1 antibody in ascites and culture fluids, the selective toxicity of this antibody towards SCC cells, the efficacy of a single treatment with antibody, optimum lytic activity at $37^{\circ} \mathrm{C}$, and the ability to fix human complement, all favor the application of this antibody for in vitro and possibly in vivo immunotherapy.

SM-1 antibody has potential usefulness, therefore, in the eradication of SCC cells from contaminated marrows. We have also described other monoclonal antibodies with selective toxicity for SCC of the lung (13). The combined use of these antibodies may allow highly efficient killing of SCC. However, the clinical advantage of antibody treatment of bone marrows before autologous bone marrow transplantation of SCC patients still needs to be evaluated. We have found in a previous study that the use of SM-1 antibody allows detection of SCC metastasis in a high proportion of bone marrow specimens from SCC patients, which could not be detected by conventional histological stains, such as Wright-Giemsa stains of bone marrow aspirates and hematoxylin-eosin stains of bone marrow biopsies (8). A prospective study to evaluate the prognostic significance of this marrow contamination among SCC patients undergoing autologous bone marrow transplantation has been initiated in this institution.

In future programs, we will then be able to evaluate the importance of the use of antibodies, such as SM-1, in clearing SCC metastasis to the bone marrow. In addition, animal studies are in progress to determine the usefulness of SM-1 antibody in serotherapy of SCC tumor in vivo.

\section{Acknowledgments}

This work was supported in part by National Cancer Institute grants CA 36498 and CA 33847. Dr. Mabry was supported by Brocton Veterans Administration Medical Center. We are grateful to Dr. G. Cannelos and Dr. E. Frei III for helpful discussions.

\section{References}

1. Cohen, M. H., and M. J. Matthews. 1978. Small cell bronchogenic carcinoma: a distinct clinicopathologic entity. Semin. Oncol. 5:234243.

2. Hansen, M., H. H. Hansen, and P. Dombernowsky. 1980. Long term survival in small cell carcinoma of the lung. J. Am. Med. Assoc. 244:247-250. 
3. Spitzer, G., K. Dicke, J. Litam, D. Verma, A. Zander, V. Lanzotti, M. Validivieso, K. McCredie, and M. Samuels. 1980. High dose combination chemotherapy with autologous bone marrow transplantation in adult solid tumors. Cancer. 45:3075-3085.

4. Souhami, R., P. Harper, D. Linch, C. Trask, A. Goldstone, J. Tobias, S. Spiro, D. M. Geddes, and J. Richards. 1982. High-dose cyclophosphamide with autologous marrow transplantation as initial treatment of small cell carcinoma of the bronchus. Cancer Chemother. Pharmacol. 8:31-34.

5. Glode, L. M., W. Robinson, D. Hartmann, J. Klein, M. Thomas, and N. Morton. 1982. Autologous bone marrow transplantation in the therapy of small cell carcinoma of the lung. Cancer Res. 42:42704275.

6. Stewart, P., C. Buckner, E. Thomas, C. Bagley, W. Bensinger, R. Clift, F. Appelbaum, and J. Sanders. 1983. Intensive chemoradiotherapy with autologous marrow transplantation in small cell carcinoma of the lung. Cancer Treat. Rep. 67:1055-1059.

7. Stahel, R. A., R. W. Takvorian, A. T. Skarin, and G. P. Canellos. 1984. Autologous marrow transplantation following high dose chemotherapy with cyclophosphamide, BCNU and V016 in small cell carcinoma of the lung and a review of the literature. Eur. J. Cancer Clin. Oncol. 20:1233-1238.
8. Stahel, R., M. Mabry, A. Skarin, J. Speak, and S. Bernal. 1985. Detection of bone marrow metastasis in small cell carcinoma of the lung by monoclonal antibodies. J. Clin. Oncol. In press.

9. Bernal, S. D., and J. A. Speak. 1984. Membrane antigen in small cell carcinoma of the lung defined by monoclonal antibody SM1. Cancer Res. 44:265-270.

10. Griffin, J. D., J. Ritz, R. P. Beveridge, J. M. Lipton, J. F. Daley, and S. Schlossman. 1983. Expression of MY7 antigen on myeloid precursor cells. Int. J. Cell Cloning. 1:33-48.

11. Bast, R. C., J. Ritz, J. M. Lipton, M. Feeney, S. E. Sallan, D. G. Nathan, and S. F. Schlossman. 1983. Elimination of leukemic cells from human bone marrow using monoclonal antibody and complement. Cancer Res. 43:1389-1394.

12. Bernard, A., L. Boumsell, and T. Borsos. 1975. Complement inhibitors released by leukocytes. III. Evidence for a new $\mathrm{C} 1$ inhibitor in the supernatant of short term cultures of mouse spleen and thymus cells. J. Immunol. 115:1091-1102.

13. Stahel, R. A., M. Mabry, K. Sabbath, J. A. Speak, and S. D. Bernal. 1985. Selective cytotoxicity of murine monoclonal antibody LAM2 against human small cell carcinoma in the presence of human complement: Possible use for in vitro elimination of tumor cells from bone marrow. Int. J. Cancer. In press. 